\title{
Measuring grain size and identifying Near Eastern cereal domestication: evidence from the Euphrates valley
}

\author{
George Willcox* \\ Centre National de la Recherche Scientifique, Institut de Préhistoire Orientale, Archéorient, Jalès, Berrias 07460, France
}

Received 4 September 2002; received in revised form 20 February 2003; accepted 8 July 2003

\begin{abstract}
Cereal grains recovered from recent excavations at two early Neolithic tenth millennium (BP non cal.) sites on the Euphrates were measured. The results presented as scatter diagrams showed that there was an increase in grain size between early and later levels. This led to the question of whether or not the changes were due to the effects of domestication. The data provided an opportunity to evaluate the use of measurements as a method to identify morphological domestication from early farming sites. Results were compared to domesticated specimens from a site dating to the end of the seventh millennium situated in the same geographical area and it was found that the upper size range from the Neolithic levels corresponded well with domesticated grains. Data from some published sites was also plotted. The factors affecting grain size such as morphological domestication, charring, environmental factors and crop processing are discussed in relation to the results.
\end{abstract}

(C) 2003 Elsevier Ltd. All rights reserved.

Keywords: Domestication; Grain size; Near East; Cereals; Neolithic; Chalcolithic

\section{Introduction}

An increase in grain size is one of the traits or consequences of domestication of Near Eastern cereals ([7]:63 [18]:19). This can be seen most readily for emmer by comparing present-day domestic accessions (Triticum dicoccum), which have plump grains, to the slimmer grains of wild populations ( $T$. dicoccoides). The differences are less marked for barley (Hordeum distichon and $H$. spontaneum) and difficult to assess for two-grained einkorn ( $T$. boeoticum ssp thauodar), because present-day domestic representatives are extremely rare. Comparisons between ancient charred material and modern grains can be misleading because accessions have been grown under optimal conditions, which is not the case for archaeobotanical material. In addition crops have evolved considerably over the last seven or eight millennia and may no longer resemble their ancestors. When or how the augmentation in

\footnotetext{
* Corresponding author. Tel.: +33-(0)-4-75-89-80-20/24; fax: +33-(0)-4-75-89-80-22

E-mail address: g.willcox@wanadoo.fr (G. Willcox).
}

grain size occurred has not been clearly established. Moreover, domestication is just one factor that could affect grain size; others include environmental conditions, genetic variability, crop processing and, for archaeological material, conditions of charring.

Measuring grain size is a descriptive method that has been used on early Neolithic sites in the Near East by a number of researchers. Over the past twenty years data on grain size from early Neolithic sites has become available. Using both her own data and van Zeist's, Colledge presented much of the information available $[1,2]$. Unusually plump grains have been identified at several early Neolithic sites, for example, at Cayönü in Turkey [17], at Jerf el Ahmar [14] and Abu Hureyra [4,5] in Syria, at Zad 2 in Jordan ([3]:143) and at Mylouthkia in Cyprus ([10]:44) (for site locations see Fig. 1). Charred spikelet bases and rachis material, which can also be used to identify domestication based on whether the ear shatters or not, were absent from Abu Hureyra, where domestication was reported on the basis of some plump rye grains among a population that was essentially wild. At Jerf el Ahmar and Zad 2 the spikelet bases were wild and here the authors were more cautious. At Cayönü 


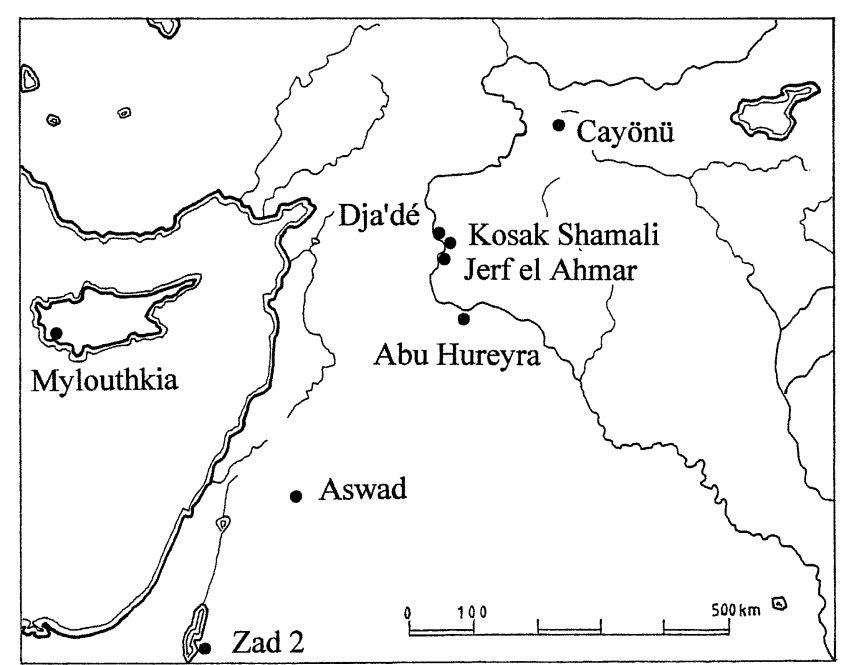

Fig. 1. Map giving locations of sites mentioned in the text.

and Mylouthkia spikelet bases of emmer and einkorn were reported to be domesticated along with the grains.

Experimental charring has shown that grains shrink in the length axis and puff in the breadth and thickness axes when subjected to heat under reducing conditions. Results of the effects of charring are given by Renfrew who charred grains at $200{ }^{\circ} \mathrm{C}$ for $12 \mathrm{~h}$ ([11]:10). Colledge also provides results from grains charred at $230{ }^{\circ} \mathrm{C}$ ([2]:122). She found that the wild archaeological grains were smaller than experimentally charred wild grains. Experimental results carried out under my supervision (unpublished data) show that puffing could increase breadth by up to $35 \%$. Hulled spikelets from several wild populations were charred at approximately $350{ }^{\circ} \mathrm{C}$ for $3.5 \mathrm{~h}$ in a bed of sand. The resulting charred grains showed excessive puffing compared to archaeological material. Experimental charring has not for the moment replicated archaeological conditions; therefore the results obtained could be misleading.

\section{Material and methods}

In this study the method adopted by Colledge was used in which breadth and thickness are measured for each grain and the results are presented in the form of scatter diagrams [1]. Many archaeological grains are broken, but, by using this method incomplete grains can be measured, which increases sample size and enables different populations to be readily compared in scatter diagrams. Measurements of all grains were obtained using an image-processing programme, with a calibrated measuring facility, connected to a stereo microscope equipped with a camera. Measurements were taken from the widest point on each grain.

Early Neolithic material for this study was recovered by flotation from Jerf el Ahmar and Dja'dé (Fig. 1) situated on the Euphrates in northern Syria [13-15]. The former produced eleven radiocarbon dates indicating that the early levels were occupied between 9800 and 9700, the later levels between 9300 and 9200 BP non cal. [12]. Thus there was a minimum of 400 years between these two occupation levels. The site of Dja'dé with thirteen dates is later, and samples came from levels dated to between 9400 and 9000 BP non cal. At both these sites cultivation of cereals was suspected because of the presence of a weed assemblage. The two cereal taxa which could have been subjected to the selective pressures of domestication were two-grained wild einkorn and/or rye ( $T$. boeoticum/urartu/Secale) and barley (H. spontaneum/distichon) [13,15]. Spikelet bases show wild-type abscission scars for rye and einkorn and over $90 \%$ of barley rachis fragments are of wild type. It has been shown that in present-day wild populations basal spikelets representing approximately $10 \%$ remain intact as in domesticated populations [6].

In order to establish whether the grains from the two Neolithic sites were wild or domesticated it was necessary to compare them with a reference set. Modern domesticates from the area would not have been comparable for reasons stated above, thus measurements from domestic grains were obtained from the Chalcolithic site of Kosak Shamali (Fig. 1), situated on the Euphrates in the same region where domesticated two-grained einkorn, emmer and barley, were recovered from burnt storage structures dated to $6050 \pm 100 \mathrm{BP}$ non cal. ([8]:160). The emmer from Kosak Shamali was compared to published data from two early Neolithic sites, Aswad in southern Syria and Cayönü in eastern Turkey $[16,17]$.

\section{Results}

Results are presented in the form of scatter diagrams. Each point represents measurements from a single grain; thickness is given in the $y$-axis and breadth in the $x$-axis. Grains of rye and einkorn from Jerf el Ahmar and Dja'dé could not be separated on the basis of their morphology; however, identification of a small number of spikelet fragments indicated that both taxa were present (Fig. 2 plots A, B, C). The early levels at Jerf el Ahmar produced a cluster of small grains, which is distinct from the domesticated grains from Kosak Shamali (Fig. 2 plot A). Later levels from Jerf el Ahmar, which are at least 400 years younger, produced grains with a much higher size range (Fig. 2 plot C). This second spread is comparable in size and corresponds to the domesticated grains from Kosak Shamali (Fig. 2 plot A and B). Measurements from the site of Dja'dé (Fig. 2 plot B) produced two clusters one similar to that of the early levels at Jerf el Ahmar and another with a higher size range similar to those from Kosak Shamali. Fig. 2 plot $\mathrm{D}$ gives the means from the earliest levels at 

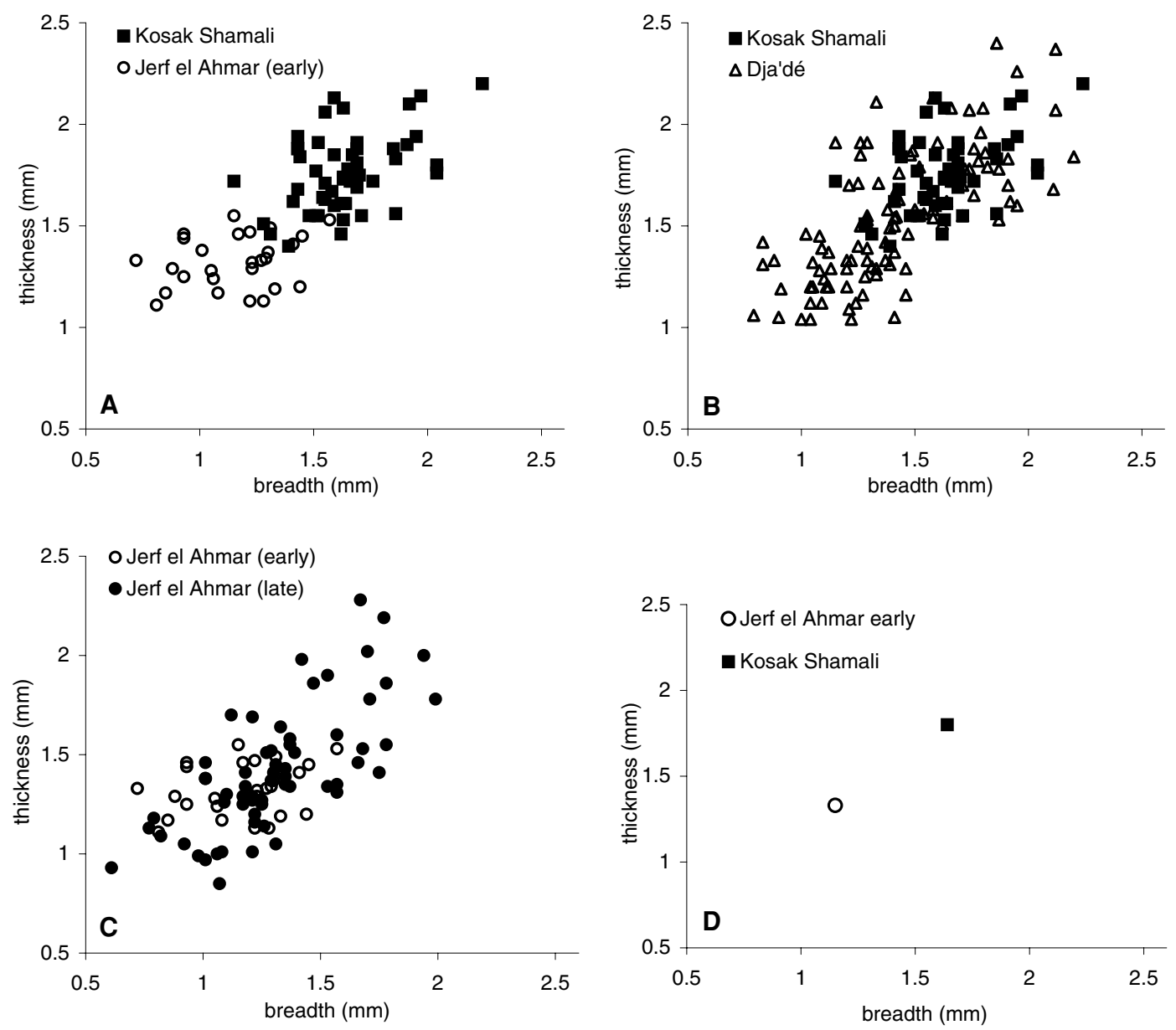

Fig. 2. Scatter diagrams giving plots of grains measured from domesticated two-grained einkorn from Chalcolithic Kosak Shamali (plot A); where it is compared to the early levels from Jerf el Ahmar, they fall into two distinct clusters. Plot B gives the measurements from the site of Dja'dé, which also fall into two similar clusters. Plot C compares early and late levels from Jerf el Ahmar where we see the appearance of large grains in the later levels comparable in size to domesticated grains from Kosak Shamali. The distinction between wild rye and wild einkorn grains is not possible, thus grains from Dja'dé and Jerf el Ahmar may represent both taxa. Plot D gives the means for the two populations, which are pure.

Jerf el Ahmar that represent only the small grains and those from Kosak Shamali, which represents only the large sized grains.

For barley, the early levels at Jerf el Ahmar produced small grains compared to the domesticated grains from Kosak Shamali (Fig. 3 A). The late levels from Jerf el Ahmar (Fig. 3 B) show a considerable increase in size compared to the early levels and the upper size range is comparable to that of the domesticated grains from Kosak Shamali. Dja'dé (Fig. 3 C) produced a wide size range from small grains similar to those from the early levels at Jerf el Ahmar and a large size range comparable to Kosak Shamali. Fig. 3D gives the means from all four archaeological levels. The most significant is the mean from the early levels at Jerf el Ahmar and the mean from domesticated grains from Kosak Shamali because these two levels represent single populations.

The measurements of domesticated emmer grains obtained from Kosak Shamali are slightly larger in size compared to the early Neolithic sites (Fig. 4). Data from
Aswad were based on maximum, minimum and average $(N=40)$, given in the published report [16]. Taken as a whole, the size distribution of emmer grains from Kosak Shamali, Aswad II and Cayönü demonstrate a slight diachronic increase in size, and as van Zeist noted, the early levels from Cayönü in eastern Turkey produced smaller, narrow wild type grains and the upper levels larger plumper grains ([17], tables 5 and 6 fig. 7.1).

\section{Discussion}

These measurements indicate a diachronic increase in grain size for the three taxa. This is clearly demonstrated by the plots of the means for the Neolithic levels and the Chalcolithic period. The sites share similar environmental conditions being located in the same region. This increase in size of the charred grains could result from various factors, which we will now examine.

Crop processing activities such as the use of sieves to remove weeds would also remove tail grain, and this 

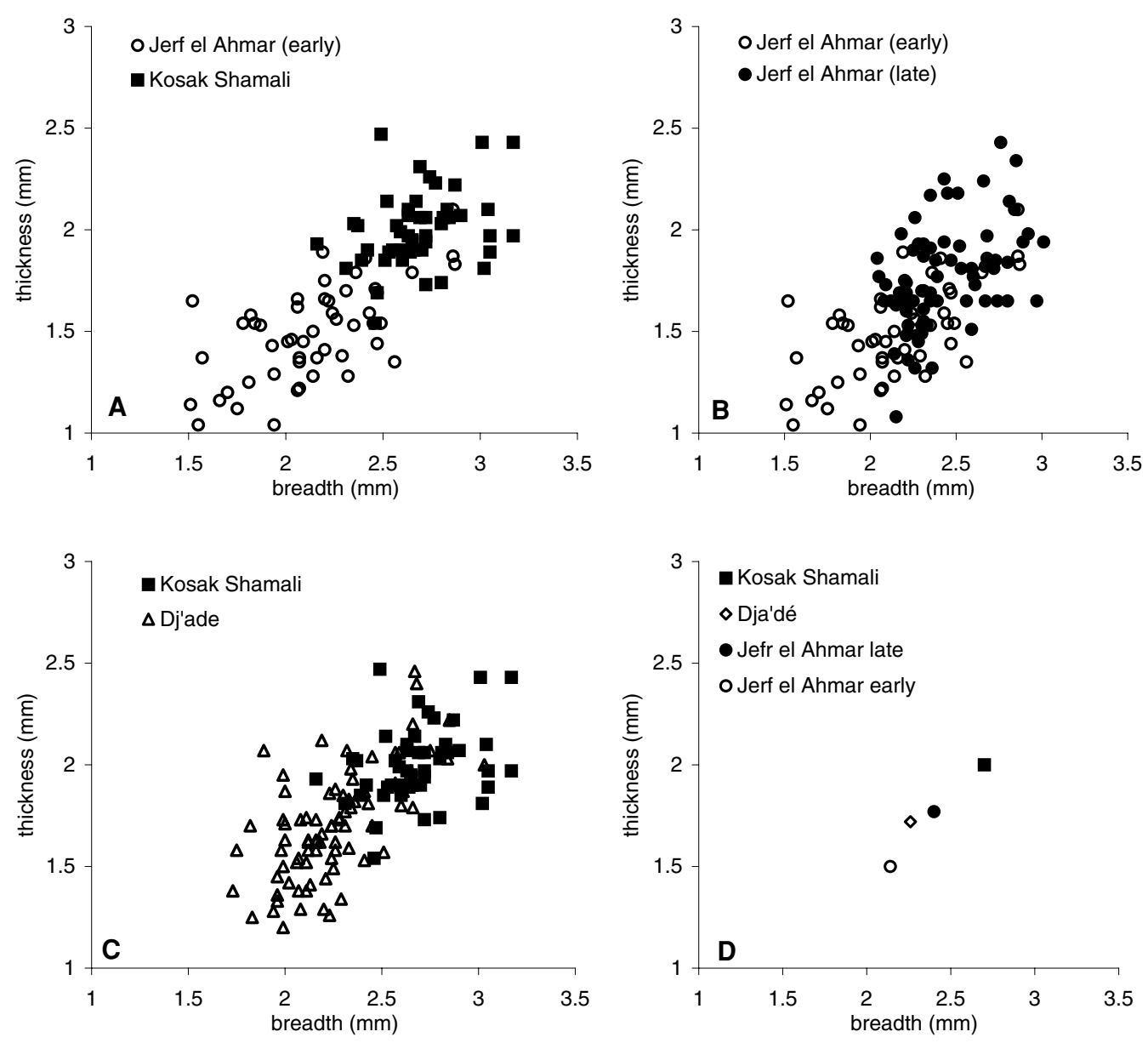

Fig. 3. Scatter diagrams comparing measurements of Neolithic barley grains with those from Chalcolithic Kosak Shamali. In plot A, early levels from Jerf el Ahmar show a distinct cluster compared to the domesticated grains from Kosak Shamali. In plot B we can see the clear increase in size between the two Neolithic levels, while in plot C the site of Dja'dé shows a mixture. Plot D shows the progressive increase in size of the means from each level.

would effect grain size. Thus cleaned grain would have on average a bigger size range than the residue from grain cleaning. This could be an explanation for the presence of small grains from the earliest Neolithic levels. However because the samples from the sites of Jerf el Ahmar and Dja'dé come from a wide variety of archaeological contexts, it is improbable that only tail grain was recovered from the early levels. The fact that the large size range from the Neolithic levels corresponds to that of Kosak Shamali is significant.

An alternative explanation for the increase in size is that growing conditions became more favourable, which would increase the frequencies of plump well-formed grains. This might have happened when cereals were brought into cultivation for the first time by early farmers who deliberately chose fields where soils had good moisture retention. In this case we would expect an increase in the frequencies of well-formed grains. But this is not the case, rather what we see is the appearance of grains representing a much bigger size range.
The effects of charring on grain size are difficult to assess for the archaeobotanical material. So far experimental data has not provided a set of reference data which may be used for comparison. Certainly what is clear is that charring will increase size variation through both puffing and shrinkage. In order to compare the size ranges between different levels and different sites we must assume that conditions of charring were fairly uniform. This would appear a reasonable assumption and bearing in mind that the most significant result is the similarity in the maximum size range between some Neolithic levels and the domesticated grains from Kosak Shamali.

This leaves us with the possibility that the increase in grain size could have a genetic basis. Genetic change at the population level could result from, (a) conscious selection, (b) unconscious selection or (c) the introduction of plump grained varieties from elsewhere. Little is known about the process of selection for plump grains, whether unconscious or conscious. The selection process 

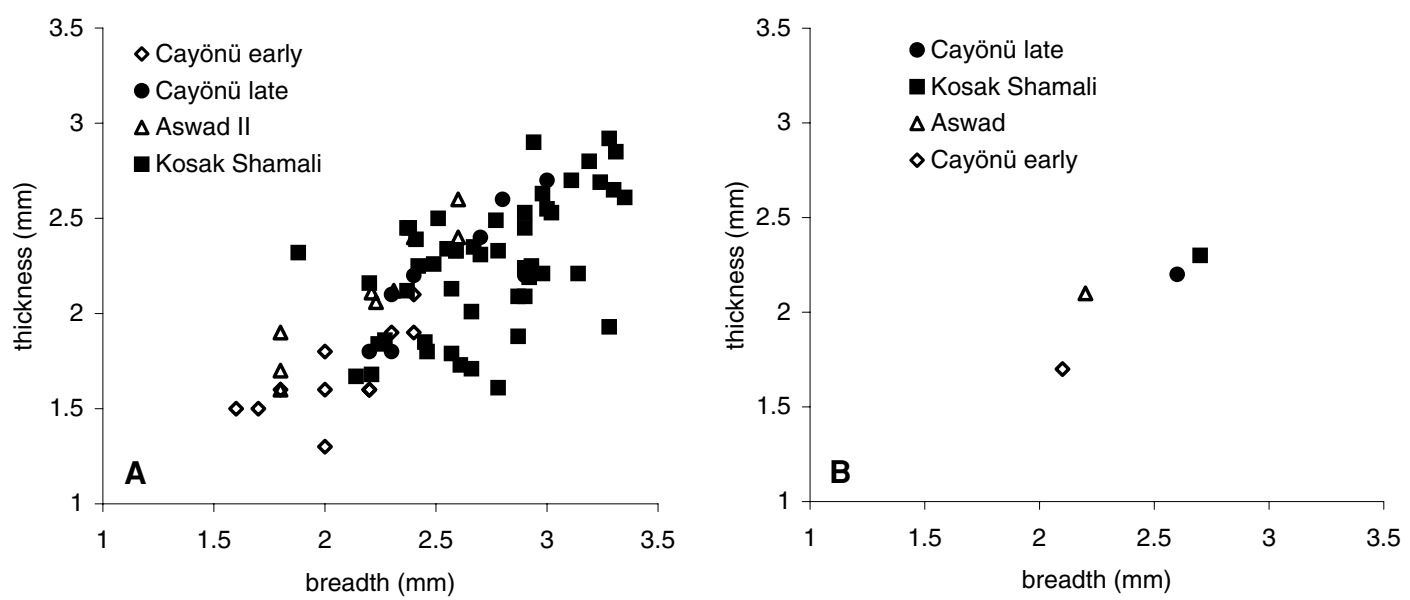

Fig. 4. Scatter diagrams comparing measurements of emmer from Neolithic sites published by van Zeist [16,17] to those of domesticated emmer from Kosak Shamali. There is evidence for a small increase in size during the early Neolithic.

is complicated by the fact that most variability in grain size is phenotypic in origin resulting from the position of grains on the ear, and to a lesser extent environmental factors which affect growing conditions. This means that conscious selection for plump grains will not lead to a rapid increase in grain size at the population level because the variability is not genetically controlled. Furthermore, grain size is probably controlled by multiple genes, which would make selection extremely slow. Natural unconscious selection would also have been very slow for the reasons mentioned above, indeed why under cultivation large sized grains were favoured, while in the wild they were apparently not, remains unexplained. Perhaps the simplest way to select for a population with big grains would be for early farmers to locate and introduce naturally occurring ecotypes with bigger grains from elsewhere. This would account for any sudden increase in grain size detected in archaeological samples. This large grained variety might then diffuse over a wider region and we might expect to find it with or without a shattering ear.

Let us now look again in detail at the plots for each taxon. Fig. 2 gives the plots of two-grained einkorn from Kosak Shamali and what may be a mixture of rye and two-grained einkorn from the two Neolithic sites. Two populations are clearly represented by two clusters. The smaller is clearly visible in the early levels from Jerf el Ahmar and the bigger represented by Kosak Shamali (plot A). In the later levels at Jerf el Ahmar (plot C), we see the appearance of bigger grains which correspond to those from Kosak Shamali which have been identified as domesticated two-grained einkorn on the basis of spikelet bases. At Dja'dé (plot B) we have a mixture of both types (plot B) which fall into two clusters. The small grains appear to represent either wild einkorn or, wild rye, or both. Evidence from chaff identifications shows that, of the seven spikelet bases from the lower levels, all were identified as rye on the basis of their glume morphology, while in the upper levels, spikelet bases of both einkorn and rye occurred. This leads one to suspect that the clusters of smaller grains are dominated by rye and the larger grains, which only appear in the later levels, are those of einkorn. The sudden appearance of this large grained population suggests that the inhabitants brought it in from elsewhere. Strong cultural affinities with sites further north, where einkorn was frequent, support this theory $[9,12]$. The clusters produced by the plump grains from Dja'dé and Jerf el Ahmar are close to those from Kosak Shamali. Thus there was no augmentation in size between these late tenth millennium populations and the Chalcolithic.

Plots of barley (Fig. 3A) from the earliest levels at Jerf el Ahmar and Kosak Shamali fall into two distinct overlapping clusters. The later levels from Jerf el Ahmar and Dja'dé show an increase in the upper size range and these plump grains correspond well with the domesticated grains from Kosak Shamali (Plot B, C, D). The increase in size between the earliest and latest levels at Jerf el Ahmar is indisputable. The size of the grains from the later levels corresponds with that of from Kosak Shamali, suggesting that we have a domesticated population. Yet rachis fragments from Jerf el Ahmar and Dja'dé are overwhelmingly of the wild type and those from Kosak Shamali are domesticated.

Plots of emmer (Fig. 4) show an increase in size from older to younger levels. Even if some of the grains in the lower size range were einkorn there is still a net increase. This is clearly seen when comparing the early and late levels from Cayönü. As with the other taxa the upper size range from the Neolithic levels is similar to the cluster produced by the domesticated grains from Kosak Shamali.

In conclusion, the indisputable diachronic increase in size of all three taxa suggests that we are dealing with a 
genetic change at the population level, as opposed to phenotypic variation. The bimodal plots for einkorn/rye and to lesser extent for barley suggest two populations. The large size range from the Neolithic sites corresponds to the domesticated grains from Kosak Shamali. Similar results were obtained by Sue Colledge [10]. She presented plots for emmer, einkorn and barley from a large number of Near Eastern sites which also produced bimodal plots of corresponding size ranges to the results presented here. This corroboration adds weight to the reliability of the method and verifies the results. For Sue Colledge the small grains are wild, the bigger ones domesticated for each of the three taxa. In both studies the increase in size occurs during the early Neolithic. If the increase resulted from the long term pressures of selection under cultivation then one would expect a change to non-shattering ears but the shattering ears persist at Jerf el Ahmar and Dja'dé. Thus the size change appears to result from the introduction of plump grained ecotypes from elsewhere, and the solid ear character did not appear until later. The plump grains from the later periods at Jerf el Ahmar and Dja'dé have the same size range as the domesticated population with non-shattering ears from Kosak Shamali. Thus there was no increase in grain size between the late tenth millennium and the late seventh millennium (BP non cal.), at least within the confines of this investigation, indicating that grain size was stable following the initial increase. Finally, this study shows that measuring charred grains does appear to be a valuable research tool in identifying changes in grain size which are linked to domestication, provided samples are numerically viable. The identification, in two separate studies of a bimodal pattern which indicates a jump in size during the early Neolithic is promising and will, it is hoped, encourage researchers to make more measurements in the future to help elucidate the little understood process of cereal domestication in the Near East.

\section{Acknowledgements}

My appreciation must go first to W. van Zeist and Sue Colledge who pioneered this work. I also wish to thank the numerous members, both Syrian and French, who participated in the archaeological excavations which, made this work possible. Finally constructive criticism from Sue Colledge and two anonymous reviewers enabled me to make important improvements in the final version of this article.

\section{References}

[1] S. Colledge, Plant exploitation on Epipalaeolithic and Early Neolithic sites in the Levant, British Archaeological Reports, International Series, 986, Oxford, 2001.

[2] S. Colledge, Plant exploitation on Epipalaeolithic and early Neolithic sites in the Levant, Ph.D. Thesis, University of Sheffield, 1994.

[3] P. Edwards, S. Falconer, P. Fall, I. Berelov, C. Davies, J. Meadows, C. Meegan, M. Metzger, G. Sayej, Archaeology and environment of the Dead Sea Plain: preliminary results of the first season of investigations by the joint La Trobe University/Arizona State University Project, Annual of the Department of Antiquities of Jordan. 45 (2001) 135-157.

[4] G. Hillman, Plant food economy of Abu Hureyra, in: A. Moore, G. Hillman, T. Legge (Eds.), Village on the Euphrates, from foraging to farming at Abu Hureyra, Oxford University Press, Oxford, 2000, pp. 372-392.

[5] G. Hillman, R. Hedges, A. Moore, S. Colledge, P. Pettitt, New evidence of Late Glacial cereal cultivation at Abu Hureyra on the Euphrates, Holocene 11 (4) (2001) 383-393.

[6] M. Kislev, Predomesticated cereals in the pre-pottery Neolithic A period, in: I. Hershkovitz (Ed.), Man and Culture in Change, BAR, Int. Series 508 (1), Oxford, 2000, pp. 147-151.

[7] M. Nesbitt, D. Samuel, From staple crop to extinction? The archaeology and history of hulled wheats, in: S. Padulosi, K. Hammer, J. Heller (Eds.), Hulled Wheats. Proceedings of the First International Workshop on Hulled Wheats 21-22 July 1995, International Plant Genetic Resources Institute, Rome, 1996.

[8] Y. Nishiaki, T. Matsutani, Kosak Shamali, Vol. 1 1UMUT Monograph 1, The University of Tokyo, Tokyo, 2001.

[9] R. Pasternak, Investigations of botanical remains from Nevali Cori PPNB, Turkey, in: A. Damania, J. Valkoun, G. Willcox, C. Qualset (Eds.), The Origins of Agriculture and Crop Domestication, ICARDA, Aleppo, Syria, 1998, pp. 170-177.

[10] E. Peltenburg, S. Colledge, P. Croft, A. Jackson, C. McCartney, M.A. Murray, Neolithic Dispersals from the Levantine Corridor: a Mediteranean Perspective, Levant 33 (2001) 35-64.

[11] J. Renfrew, Palaeoethonobotany, Methuen, London, 1973.

[12] D. Stordeur, F. Abbès, Du PPNA au PPNB: mise en lumière d'une phase de transition à Jerf el Ahmar (Syrie), Bulletin de la Société préhistorique française 99 (3) (2002) 563-595.

[13] G. Willcox, Charred plant remains from a 10th millennium kitchen at Jerf el Ahmar (Syria), Vegetation History and Archaeobotany 11 (2002) 55-60.

[14] G. Willcox, Evidence for plant exploitation and vegetation history from three Early Neolithic pre-pottery sites on the Euphrates (Syria), Vegetation History and Archaeobotany 5 (1996) 143-152.

[15] G. Willcox, S. Fornite, Impressions of wild cereal chaff in pisé from the tenth millennium at Jerf el Ahmar and Mureybet: northern Syria, Vegetation History and Archaeobotany 8 (1999) 21-24.

[16] W. van Zeist, J.A.H. Bakker-Heeres, Archaeobotanical studies in the Levant 1. Neolithic sites in the Damascus basin: Aswad, Ghoraifé, Ramad, Palaeohistoria 24 (1982) 165-256.

[17] W. van Zeist, G.J. de Roller, The plant husbandry of aceramic Çayönü, SE Turkey, Palaeohistoria 33/34 (1994) 65-96.

[18] D. Zohary, M. Hopf, Domestication of Plants in the Old World, Oxford University Press, London, 2000. 